\title{
Albumin Consisted Carriers Might Be Protected from Proteases
}

\author{
Danielyan Kristine E* and Chailyan Samvel G \\ H Buniatian Institute of Biochemistry, National Academy of Science of Armenia, Armenia
}

*Corresponding author: Danielyan Kristine E, H Buniatian Institute of Biochemistry, National Academy of Science of Armenia, Armenia

\section{ARTICLE INFO}

Received: 幽 May 07, 2020

Published: 慧 June 09, 2020

Citation: Danielyan Kristine E, Chailyan Samvel G. Albumin Consisted Carriers Might Be Protected from Proteases. Biomed J Sci \& Tech Res 28(2)-2020. BJSTR. MS.ID.004613.

Keywords: Proteases; Inhibitors; Viruses, Albumin; Micropartciles
ABSTRACT

Inhibitors of the proteases might be of the direct utility for the medical treatment aids as well as might serve as the protective shells for the other agents, which might be damaged due to the effect of blood proteases. The example is the delivery of the peptides, which might be antibiotics or the hormone type compounds, peptide type inhibitors of the viruses replication responsible enzymes, vasopressin or oxytocin. Previously (results are in press) there were leaded the experiments and included the general inhibitors of the proteases, such as urea, into the composition of the albumin nanoparticles It was detected how stable these particles during the trypsinolyses over the 72 hours. We concluded, the general inhibitors were able to stand as the protective agents, preventing lyses of the micropartciles, made from albumin. Such formulations might serve as the wonderful carriers in blood stream for the transportation of medical compounds of the peptide or protein nature, antibiotics, inhibitors of the replicases of viruses, protecting them from the proteases of blood.

\section{Introduction}

Proteases are the group of the enzymes, responsible for the cleavage of the proteins and peptides. Otherwise, they are called hydrolases. These groups of the compounds are ubiquitous and in the higher organisms they are encoded by the $2 \%$ of the genes. The best characterized proteinases are the mammalian digestive enzymes-trypsin, chymotrypsin, and pepsin and the lysosome enzymes-cathepsin B and cathepsin D. In physiological conditions these enzymes carry out the limited proteolysis of the numerous zymogen forms of the enzymes, responsible for blood clotting and lyse the fibrin clot [1].

Inhibitors of the proteases might be used in different fields: as the antimicrobial, antiviral compounds, as the protective shells for the peptide-types antibiotics etc. Numerous protease inhibitors were tested at the level of the "bench side" and many of them passed through the animal-based in vivo studies. The main field of the applicability of the protease inhibitors is the medicine and treatment of the human beings against of the pathogen viruses, bacteria [2], against the development of the inflammation [2], cardiovascular diseases [3], respiratory related pathologies [2], neurodegenerative diseases, particularly Alzheimer's disease [4].
However, just several protease inhibitors are accepted into the medical practice. The list of such inhibitors includes the ACE (angiotesine converting enzymes) inhibitors, HIV-1 protease inhibitors for treating HIV/AIDS, inhibitors of the thrombin for the treatment of the stroke and cardiovascular diseases as well as the elastases for the treatment of the Systemic Inflammatory Response Syndrome (SIRS).

The HIV protease, encoded in the $5^{\prime}$ end of the pol gene, is expressed as the part of the gag-pol polyprotein [5]. This gene encodes a 99-amino-acid protein. Homodimers of this protein have the aspartyl protease activity that is typical for retroviral proteases; monomers are enzymatically inactive [6]. The protease of HIV is targeting gag and gag-pol polyproteins, separating it into the several parts: large proteins, which are structure building responsible p24, p17, and p7 and small proteins, which are p6, p2, and p1, with undefined functions [7]. It is interesting, mammalian proteases are not efficiently cut the HIV proteins because the HIV proteases possess with the unusual space specify, cleaving the bonds between phenylalanine-proline or tyrosine-proline [8]. After the cleavage of gag polyprotein the morphologic changes in 
the virion occur and condensation of the nucleoprotein core might be formed [9]. In case, if the proteases transcription is defective the immature, noninfectious viral particles are formed [10].

The four inhibitors of aspartyl - proteases of HIV have the medicinal utility. Indinavir (Crixivan), nelfinavir (Viracept), ritonavir (Norvir), and saquinavir (Invirase and Fortovase) and the investigational protease inhibitor amprenavir are structurally related molecules. Most contain a synthetic analogue of the phenylalanine-proline sequence at positions 167 and 168 of the gag pol polyprotein that is cleaved by the protease [8].

HIV-protease inhibitors prevent cleavage of gag and gagpol protein precursors in acutely and chronically infected cells, arresting maturation and thereby blocking the infectivity of nascent virions [11]. The main antiviral action of HIV-protease inhibitors is thus to prevent subsequent waves of infection; they have no effect on cells already harboring integrated proviral DNA.

Translation of the replicase proteins in coronaviruses is initiated by the translation of ORF1a and, ORF1ab via a-1 ribosomal frame-shifting mechanism [12]. Due to the proceeding of mentioned mechanism two large viral polyprotein, pp1a and pp1ab, that are further process by two virally encoded cysteine proteases, the papain-like protease (PLpro) and a 3-chymotrypsinlike protease (3CLpro), which is sometimes referred to and is called as the main as main protease (Mpro) $[13,14]$. Processing of the viral polyprotein is required for the release and maturation of 16 viral proteins (non-structural proteins or nsps) involved in the formation of a membrane-associated, cytoplasmic enzyme complex, the replicase complex, which is responsible for directing the replication and transcription of the viral genome. It is thought that the establishment of viral replication sites is initiated by the recruitment of replicase proteins to host membranes, a process mediated by the several viral transmembrane domain-containing proteins such as the nsp3, nsp4 and nsp6 [15-17].

One of the best characterized drug targets among coronaviruses is the main protease Mpro, also called 3CLpro [18]. Inhibitors of the proteases might be of the direct for with the medical treatments aids as well as might serve as the protective shells for the other agents, which might be damaged due to the effect of the blood proteases. The example is the delivery of the peptides, which might be antibiotics or the hormone type compounds, peptide type inhibitors, responsible for the replication of the viruses vasopressin or oxytocin.

Albumin is not just the protein of blood, which is supporting the oncotic pressure of it but also serving as the natural carrier for the medicines or organic compounds. In our experiments, glutaraldehyde was used for the polymerization of albumin. Determination of the particle size was performed by the light as well as phase contrast microscopies and analyzed by Pixcavator 6.0 and Image Tool programs. As a consequence of the experiments, the best formulation of glutaraldehyde ratio and albumin quantity as well as conditions for the formation of the smallest sized spheroidshaped particles were found for the further in vivo application [19].

Compared the to synthetic polymers, proteins possess several advantages: they might be degraded into the peptides by naturally occurring enzymes; in comparison with the chemically synthesized nanomolecules, which accumulate in the body, particularly in the liver, and result in toxic degradation products [20]. The scientists proceeded the computer-aided design, which led to the discovery of the cyclic urea inhibitors of the HIV protease. The group of the investigators found out, that studied DMP 450 has a significant advance within the cyclic urea class of HIV protease inhibitors due to its exceptional oral bioavailability. They psoposed, that an optimal cyclic urea will provide clinical benefit in treating AIDS [21].

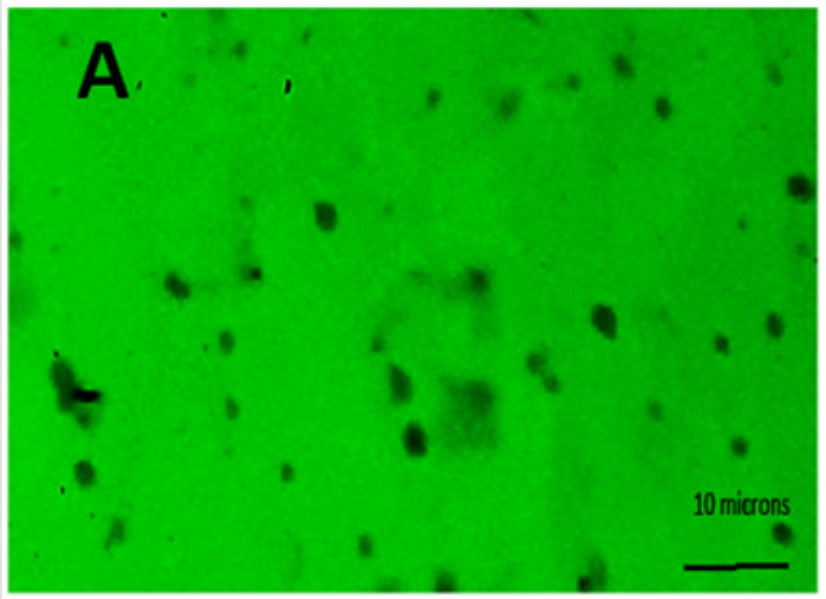

\section{B Trypsinolysis in the water environment}

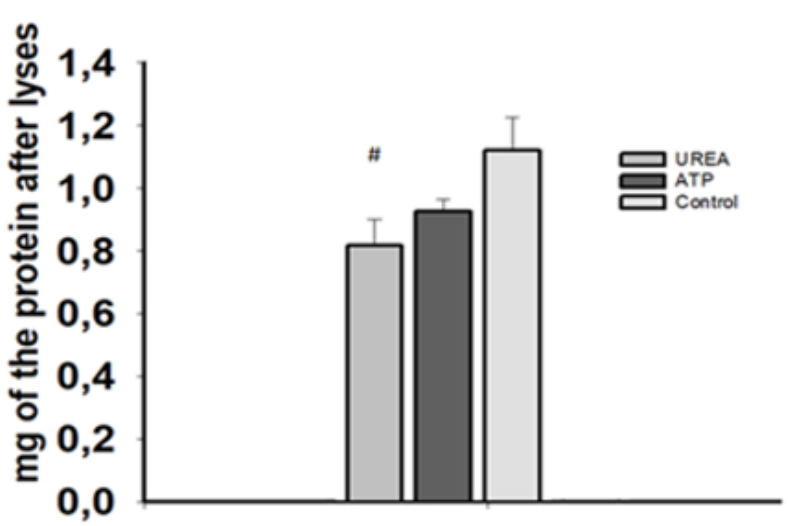

Figure 1: A. The electron microscopy picture representing formation of albumin nano and/or micro-scale particles. The lyses of the particles in the environments of water. After formation of the particles it was added trypsin. After 72 hour it was measured the quantity of the proteins in solution. The formation of the particles was performed by utility of glutaraldehyde. The results were accepted as the statistically significant, when $p<0,05$. 
During our experiments, we included the general inhibitors of the proteases, such as urea, into the composition of the albumin nanoparticles and detected how stable these particles during the trypsinolyses over the 72 hours (results are in press, Figure 1). We concluded, the general inhibitors are able to stand as the protective agents, preventing lyses of the micropartciles made from albumin. Such formulations might serve as the wonderful carriers in blood stream for the transportation of medical compounds of peptide or protein nature, antibiotics, inhibitors of the replicases of viruses, protecting them from the proteases of blood.

\section{References}

1. Raghunath TM, Shamkant BB (2010) Biological aspects of proteolytic enzymes: A Review. Journal of Pharmacy Research. 3(9): 2048-2068.

2. Bernstein PR, Edwards PD, Williams JC (1994) Inhibitors of human leukocyte elastase. Review Prog Med Chem. 31: 59-120.

3. Stubbs MT, Bode W (1993) A player of many parts: The spotlight falls on thrombin's structure. Review Thromb Res 69(1): 1-8.

4. Selkoe DJ (1997) Alzheimer's disease: Genotypes, phenotypes, and treatments. Science 275(5300): 630-631.

5. Kramer RA, Schaber MD, Skalka AM, Ganguly K, Wong-Staal F, et al. (1986) HTLV-III gag protein is processed in yeast cells by the virus polprotease. Science 231: 1580-1584.

6. Pearl LH, Taylor WR (1987) A structural model for the retroviral proteases. Nature 329: 351-354.

7. Henderson LE, Bowers MA, Sowder RC, Serabyn SA, Johnson DG, et al. (1992) Gag proteins of the highly replicative MN strain of human immunodeficiency virus type 1: Posttranslational modifications, proteolytic processings, and complete amino acid sequences. J Virol 66: 1856-1865.

8. Debouck C (1992) The HIV-1 protease as a therapeutic target for AIDS AIDS Res Hum Retroviruses 8: 153-164.

9. Overton HA, McMillan DJ, Gridley SJ, Brenner J, Redshaw S, et al. (1990) Effect of two novel inhibitors of the human immunodeficiency virus protease on the maturation of the HIV gag and gag-pol polyproteins. Virology 179: 508-511.

ISSN: 2574-1241

DOI: 10.26717/BJSTR.2020.28.004613

Danielyan Kristine E. Biomed J Sci \& Tech Res

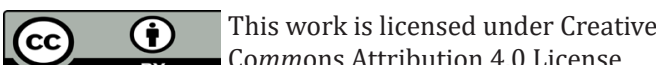

Submission Link: https://biomedres.us/submit-manuscript.php
10. Grice SFJ, Le Mills J, Mous J (1988) Active site mutagenesis of the AIDS virus protease and its alleviation by trans complementation. EMBO J 7: 2547-2553.

11. Roberts NA, Martin JA, Kinchington D, Broadhurst AV, Craig JC, et al (1990) Rational design of peptide-based HIV proteinase inhibitors. Science248: 358-3561.

12. Bredenbeek PJ, Pachuk CJ, Noten AF, Charite J, Luytjes W, et al. (1990) The primary structure and expression of the second open reading frame of the polymerase gene of the coronavirus MHV-A59: a highly conserved polymerase is expressed by an efficient ribosomal frameshifting mechanism. Nucleic Acids Res 18: 1825-1832.

13. Thiel V, Ivanov KA, Putics A, Hertzig T, Schelle B, et al. (2003) Mechanisms and enzymes involved in SARS coronavirus genome expression. J Gen Virol 84: 2305-2315.

14. Ziebuhr J (2004) Molecular biology of severe acute respiratory syndrome coronavirus. Curr Opin Microbiol 7: 412-419.

15. Kanjanahaluethai A, Chen Z, Jukneliene D, Baker SC (2007) Membrane topology of murine coronavirus replicase nonstructural protein. Virology 361: 391-401.

16. Oostra M, Hagemeijer MC, van Gent M, Bekker CP, te Lintelo EG, et al. (2008) Topology and membrane anchoring of the coronavirus replication complex: not all hydrophobic domains of nsp3 and nsp6 are membrane spanning. J Virol 82: 12392-12405.

17. Zhang L, Lin D, Sun X, Curth U, Drosten C, et al. (2020) Crystal structure of SARS-CoV-2 main protease provides a basis for design of improved $\alpha$-ketoamide inhibitors. Science 368: 409-412.

18. Anand K, Ziebuhr J, Wadhwani P, Mesters JR, Hilgenfeld R (2003) Coronavirus main proteinase (3CLpro) structure: Basis for design of anti-SARS drugs. Science 300: 1763-1767.

19. Aganyants HA, Nikohosyan G, Danielyan KE (2016) Albumin microparticles as the carriers for allopurinol and applicable for the treatment of ischemic stroke. International Nano Letters 6: 35-40.

20. Elzoghby AO, Wael M Samy, Nazik A Elgindy (2012) Protein-based nanocarriers as promising drug and gene delivery systems. J Control Release 161: 38-49.

21. Hodge CN, Aldrich PE, Bacheler LT, Chang CH, Eyermann CJ, et al. (1996) Improved cyclic urea inhibitors of the HIV-1 protease: synthesis, potency, resistance profile, human pharmacokinetics and X-ray crystal structure of DMP 450. Chem Biol 3(4): 301-314.

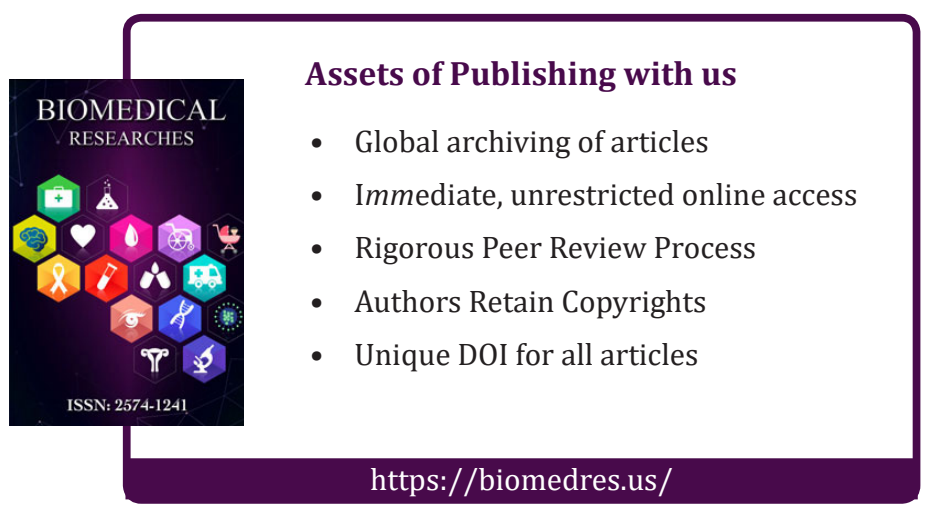

